\title{
Tools and E-tools for Memory and Attention Problems in Pre-school Education
}

\author{
http://dx.doi.org/10.3991/ijes.v3i3.4729 \\ Georgia K. Kokkalia, and Athanasios S. Drigas \\ NCSR DEMOKRITOS, Institute of Informatics and Telecommunications, Net Media Lab, Athens, Greece
}

\begin{abstract}
Recent development in the role of kindergarten in children's progress includes the use of Information and Communication Technologies (ICTs). ICT nowadays is recognized as a tool that can foster the knowledge and the experiences for this crucial age and the support of children who face difficulties in kindergarten age is thought significant. In this paper we present a list of the most representative tools and e-tools of the last decade (2005-2015) for preschool children who face memory and attention problems. The role and the significance of these tools in children's development are examined. The effectiveness of these tools is also investigated.
\end{abstract}

Index Terms-attention difficulties, memory problems, preschool education, tools

\section{INTRODUCTION}

Technology seems to be present everywhere while it is widely accepted that influences almost every aspect of everyday life. However, the society's prospect of the ICT (Information and Communication Technologies) role in education has also changed [1]. Today learners seem to be more involved in learning, as they have the advantage of the technology special means to support their assignments [2]. ICT in education can make teaching and learning more effective and efficient, because they do not involve only learning about technology but more specifically learning with technology [3].

Early childhood educational programs aim to promote various concepts, skills and attitudes and the concepts to be learned, the skills to be developed and the attitudes to be taught should all be age appropriate. As most preschool children do not have or have limited reading skills, the tools that are usually used tend to have sound, icons, animation or any combination of these [4]. Specific features of early childhood educational software that seem suitable include the appearance of pictures, sounds and the presence of different graphical features [5]. The software to be selected or adapted for early childhood education settings needs to be developmentally appropriate and to be integrated in the classroom with the appropriate pedagogic approaches [6]. Early childhood teachers have to decide about which software to use and how to adopt it in their classrooms to be sure that benefits are achieved[7] . Educator's role is important, as they have to choose the appropriate for their class software and intervene when is needed and is thought essential. However, appropriate training for all teachers and specialists that are involved in working with young children in the use of ICTs in support of learning is recommended. The computer is only a tool that has the potential to support the teaching and learning process; so even the best software needs to be used wisely [8].

Additionally, professionals in psychological, medical, scientific, and educational fields have mentioned the importance of the years between birth and five years, for learning. If there is any risk of difficulties, these early years become even more crucial [9] as there is a history of research supporting the value of early identification and intervention. One value of early identification and intervention is that it provides a base for later learning and for this reason may raise later academic success experiences for children at risk. In addition, early identification can predict secondary problems from occurring because it prevents the need for more extensive education services in the future and leads to more inclusive programming [5]. On the other hand, there has been an increasing emphasis on educating kindergarten children who need special education with the support of ICT and thus this fact has reinforced the use of technology as a way of overcoming barriers to their learning. Recent studies on the introduction of ICTs in pre-school special education argue that can provide children with additional opportunities for rich learning activities that are relevant to their growth characteristics and have positive effects in regard to their learning difficulties. However, early intervention depends on good diagnostic information while it is not enough to know simply that a pupil has problems in learning but also is necessary to understand the problems and the causes of a student's learning behaviour. As a result such understanding should then be used to develop an appropriate intervention [10].

Close links between memory functions and many aspects of learning and academic achievement in children are well established. Memory skills of children with special needs have been a domain of great research for professionals over the last years as there is evidence that shows that poor memory skills characterize children who fail to progress normally in different areas of needs [11]. however, it is well known that computerized programs seem to be a promising new approach to memory interventions as the role of technology for people with cognitive difficulties is crucial in the areas of based applications and neural networks [12]. Taking the above into consideration, early identification and intervention for children with memory problems has been strongly recommended. Many researchers think that observable behaviours in children very often indicate potential learning problems in preschool including hyperactivity, coordination problems perseveration, impulsivity, processing deficits, distractibility, and memory problems [6]. Furthermore, memory is a key component of cognition that plays an integral role in cognitive development. Memory can be divided into long 
PAPER

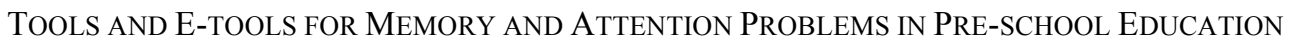

term and short-term memory. Short-term memory's main part is working memory and long-term memory consists of a declarative, procedural and perceptual representation system. Memory impairments can also have negative consequences on social factors and the sense of personal history. Additionally, this kind of deficits may affect academic performance and particularly arithmetic and can result in low self-esteem. Furthermore, poor working memory is the source of many problems related to attention and is often linked to Attention Deficit/Hyperactivity Disorder (ADHD) [13].

On the other hand, ADHD is a psychiatric diagnosis that identifies children who exhibit inappropriate levels of inattention and/or hyperactivity [14] and is associated with poor scholastic outcomes or other learning disabilities [15]. Attention difficulties are one of the most prevalent problems that become apparent during a child's schoollife and are usually characterized by poor attention skills and/or hyperactive and impulsive behaviours. These problems usually show up in early childhood and more specifically are present before the age of seven where often a diagnosis is taken place. A common misconception about children with attention problems is that they aren't paying attention and they cannot focus on a specific time for an acceptable period. This elevated risk for poor academic achievement indicates that many students with attention disorders are in need of an accurate diagnosis and effective intervention strategies because ADHD usually continues into adulthood [16]. Research suggests that successfully management and behaviour modification of this disorder often depends on the integrated program of medical interventions and behavioural techniques while a very important factor for this purpose is to involve parents and teachers in these interventions [17].

As a result of the above statements, our study is based on national and international publications as well as the research findings of the most representative studies of the last decade, which focus on the use of tools and e-tools that assess kindergarten children who face memory and attention problems. These tools seem to diagnose and intervene in kindergarteners in order to help them with their difficulties. This paper will try to make a list of the most important educational tools and e-tools that focus on diagnosis and intervention purposes of preschoolers who face memory and attention difficulties and need assessment.

\section{Educational Tools That Assess Preschool CHILDREN WiTh MEMORY PROBLEMS}

Nowadays, hundreds of experts in the areas of medicine and psychology are encouraging memory training. They've brought an important approach into practices and schools around the world and are helping people of all ages succeed in areas of their lives that are characterized by poor memory skills [18] . Generally speaking, memory is thought central to concentration, problem solving, and impulse control, is closely correlated to fluid intelligence and is a strong indicator of academic and professional success. On the other hand poor memory and especially poor working memory is the source of many problems related to attention and is often linked to Attention Deficit Hyperactivity Disorder, and other learning disabilities [11]. As a result, recent years have seen a rise in the popularity of memory training programs- tools and e-tools- to kindergarten children, because these interventions give promises of increased IQ, creativity, grades and reductions in day-to-day lapses of attention.

In order to identify and support children with working memory impairments, the Automated Working Memory Assessment (AWMA)[19] , a computerized measure for educational professionals to use to screen individuals aged 4-22 years for working memory problems has been developed. According to the above, Alloway presented the automated working memory assessment (AWMA), a standardized computerized tool that can diagnose memory problems. The purpose of the AWMA is to provide educators with a quick and effective tool to screen and support those who face memory disorders. Findings indicate that working memory skills in children with memory difficulties are usually stable over the course of the school year. This tool enables teachers and psychologists to assess memory skills with a user-friendly interface. Furthermore, AWMA includes three levels of assessment and is designed for students with suspected-especially- working memory difficulties. General speaking, AWMA is a computer-based assessment that provides three measures each of verbal short-term memory, visuo-spatial short-term memory, verbal working memory, and visuo-spatial working memory. Specifically, AWMA- short form (AWMAS) is used for screening learners who are suspected to have memory deficits, but the specific area of their difficulties is not known and AWMA- long form (AWMA-L) which is suitable for confirmation of working memory problems for learners identified as having working memory problems in the classroom. According to the developers, the test includes 12 subtests of verbal Short Term Memory (Digit Recall, Word Recall and Nonword Recall), visuo-spatial Short Term Memory (Dot Matrix, Block Recall and Mazes Memory), verbal Working Memory (Backward Digit Recall, Listening Recall and Counting Recall), and visuo-spatial Working Memory (Mr X, Spatial Span and Odd-One-Out). Lastly, the AWMA is the first standardized tool for non-specialist assessors such as classroom teachers to use to screen their pupils for significant working memory problems quickly and effectively.

Furthermore,[20] developed a battery of Internet based applications which collectively operate as a screening test of cognitive abilities capable not only to predict preschool and school age children at risk of learning difficulties but also to equip the teacher with a profile of mental abilities relevant for choosing and designing personalized programs. This study evaluated the capability of the new computerized cognitive battery of tests to predict reading performance. Specifically, the MAPS (Mental Attributes Profiling System) battery addressed eight major domains of language independent tests that have been frequently linked to learning difficulties; short-term visual memory, short-term auditory memory, auditory discrimination, visual discrimination, lateral awareness, categorization, sequential processing and navigational ability. The findings of the research suggest that this test can diagnose memory problems in children supporting the view that five domains (lateralization, auditory memory, categorization, sequencing and auditory discrimination) can be strong predictors for later reading problems. The research concludes claiming that MAPS can create a child's profile signifying abilities and problems in learning and can screen memory problems in very young children as well 
PAPER

TOOLS ANd E-TOOLS For MEMORY AND ATtention Problems In Pre-SCHOOL EDUCATION

as in children who are bilingual or multilingual offering an assessment in a broad spectrum of cognitive processes.

Additionally, one of the most widely used software tools is the Cognitive Profiling System (CoPS), a computerized psychometric assessment system that identifies the cognitive strengths and difficulties for kindergarten and primary school children [21]. CoPS is consisted of eight tests in the form of game, included phonological awareness, auditory discrimination, short term visual memory and auditory verbal memory. The total assessment time of the test is no longer than twenty minutes and is used across the UK, Scotland and British schools around the world. According to the developers, the students are tested also, in sequential and associative memory, in auditory and colour discrimination and in phonological awareness providing a picture of the child's level of development in the relevant areas at the time of school entry. Although this tool not primarily intended for diagnostic purposes, however can show children who are weak in various aspects of learning, included in memory, and thus can be used to in decision-making about appropriate teaching and learning approaches for such children. This alternative approach is an on-entry assessment program for children aged 4:0 to $5: 6$, since in order to be accredited by the Qualifications and Curriculum Authority for use in schools in England, strict criteria had to be followed. These criteria specified assessment in four key components of the early learning curriculum (communication skills, literacy, mathematics, and personal and social development). CoPS Baseline provides a snapshot of the child's level of development in the component areas at the time of school entry. However, the similarly named program Lucid Cognitive Profiling System (CoPS), with which CoPS Baseline Assessment should not be confused, is designed specifically for diagnostic purposes [21].

Moreover, another promising tool that was designed to support students at-risk for learning disabilities that might also face and memory difficulties and can be used by the students under the teacher's, special educator's or speech pathologist's supervision [22] is the APLo. APLo system is intended to be used in assessment and diagnostic phases of children's oral speech and language abilities. It is an online system that is designed to provide easy and direct access to students who face difficulties and allow, when necessary, the efficient use by other non-experts in the clinical and professional setting to be involved in oral language learning and strengthening. In particular, APLo system examines the domains of [22] articulation, phonological, fluency, and language disorders while can diagnose children with age delays, autism and mental retardation. According to the researchers, the teacher selects and incorporates suitable activities in a digital environment that can be used in the preschool setting or at the first school age to enhance phonology activities. The young students at-risk of learning disorders, that are entering the world of knowledge, can interact with the computer ensuring undiminished interest on the learning activities. Through an interdisciplinary and experiential approach the aim is to enhance phonological awareness and communication skills and accomplish the best learning outcomes. The software activities are not just a transaction of traditional exercises presented on the computer but benefit from the advantages of technology like moving images, animations, sound and interactivity that create an amusing, playful and effective learning environment according to relevant studies [22] In depth, APLo gathers data on the child's speech and language symptoms by the user who answers questions on the matter in sections such as demographics, medical/communication history, verbal communication, non-verbal communication, oral examination, articulation/phonology, structure of language, psychomotor development, sound discrimination and memory. Lastly, according to the researchers, this tool has been created according to educational standards incorporating the modern technological developments in order to function as a learning tool.

However, it is common knowledge that special needs require special attention and as a result early education lays the grounds for future development. According to a study [23] Young Digital Planet started to create applications that were designed to help children restore their curiosity and keep learning engaging, motivating and challenging. Young Digital Planet supports the view that early prevention is very important; edu- Sensus is an intervention tool that is based on intuition, designed for speech therapists and combined with the educational needs communicated by the market. According to the developers, this software has been in use in Poland for almost 10 years now and has proven to be an irreplaceable tool for early education and special needs prevention. Specifically, eduSensus is a family of products addressing all developmental needs and one of the advantages is that it has been created together with therapists, teachers, parents and children. Moreover, eduSensus Team covers a wide range of topics in the use of ICT tools in supporting the development of children who face specific difficulties including children who are at risk of dyslexia and face other problems such as memory and attention deficits, developmental disorders etc. Lastly, the designers of the eduSensus claim that this platform introduces children into the ICT world develop young learners' vocabulary and communicative skills with digital programs, offering also effective and engaging stimulation of retarded children's development and support children who face learning difficulties at the kindergarten.

Also, according to St Clair $\square$ Thompson [24] one way of providing memory strategy training is to involve computer-based teaching and practice of memory strategies. Memory Booster is a computer game that teaches memory strategies, over a period of six to eight weeks. Memory Booster [25] is an enjoyable adventure game for children that teaches and encourages the use of rehearsal, visual imagery, creating stories and making groups and according to several studies results in significant improvements on measures of working memory [24]. Memory Booster begins with an introductory story and then provides instructions about the strategy of rehearsal. Each child then is asked to remember, an item specified verbally by the computer. Then children answer by using the computer mouse to select the target amongst a number of distractors. After a number of trials instructions about visual imagery are provided and then players are asked to remember two objects on each trial using this strategy. Instructions to a third memory strategy, creating stories, are then followed by trials, which involve remembering three items. If a child successfully progresses through the program the levels then increase, to remembering four, five or six items. Children who perform particularly well also progress to being taught the strategy of grouping. Throughout Memory Booster children receive verbal 
PAPER

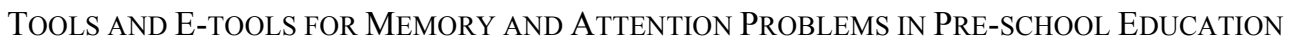

encouragement and feedback from the computer, and upon completing each level they gain rewards in the form of watching cartoons. Lastly, researchers claim Memory Booster is a tool that leads to significant improvements in working memory tasks assessing the phonological loop and central executive components of working memory.

In addition, multiple assessments of both verbal shortterm and working memory are provided in a Working Memory Test Battery standardized for children (WMTBC) [26]. WMTBC [27] includes four measures of verbal short-term memory: digit recall, word recall, non-word recall, and word list matching recall. All four measures involve verbal presentation of memory items, with the first three tests requiring immediate spoken recall. Word list matching involves the child judging whether two spoken sequences are identical or not, as it places minimal demands on phonological and articulator production skills. This test is particularly appropriate for use with children with speech-motor deficits and scores on all four measures are used to derive a standardized verbal memory composite score. The WMTB-C also includes three measures of verbal working memory (listening recall, counting recall, and backwards digit recall), scores on which are used to give a mixed working memory score. Finally, the WMTB$\mathrm{C}$ includes three measures of visuo-spatial short-term memory (matrices, mazes memory, and block recall).

A recently conducted study investigates whether preschoolers respond to the mathematical notion of most probable using their memory skills and the cognitive skills in a probabilistic game designed on the computer. This random-game, named "Shoes and Squares", gives children the chance to get involved and infer the most probable outcome among different conditions with structural changes in the composition of the sample space. Children are tested on whether the gradual alterations in the analogies and distribution of the items in every condition affect their predictions [28]. The developers claim that, preschoolers were personally engaged; they made estimations and seemed to get affected by the structural changes among the sample space. They also state that children's cognitive skills, included the memory and the attention, improved and that such finding raise educational implications concerning not only the teaching and constructing of probabilities in preschool education but also the role and use of technological means in the classroom.

Last but not least, Toki et al. [29] introduced a software tool that was designed to support the student at-risk for learning disabilities. The children under the specialist's supervision can use this tool while the teacher selects and incorporates suitable activities in a digital environment for them in order to interact with the computer during the learning activities. Through an alternative and experiential approach the aim is to enhance phonological awareness and communication skills and accomplish the best learning outcomes. The software activities can help students from the advantages of technology like moving images, animations, sound and interactivity that create an amusing, playful and effective learning environment according to relevant studies [29]. This study therefore, can be considered that contributes to the development of special educational software for students in the first school age that are at-risk of learning disabilities. Despite the fact that these digital activities focus on phonological awareness issues in a multimedia interactive and playful environment that keeps student's interest and adjusts to their needs and abilities in order to achieve the desired learning outcomes while students' creativity and communication is enhanced.

\section{Educational Tools That Assess Preschool Children With ATtention DifFiculties}

Many researchers claim that working memory (WM), the cognitive system that is responsible for the temporary storage and manipulation of information, is very important for maintaining focused behaviour in everyday situations [30] . Working memory problems are typical among individuals with attention and attention deficit hyperactivity disorder (ADHD, ) [31]. Attention problems and attention deficit hyperactivity disorder is a diagnostic category applied to individuals with high levels of problem behaviours that are inattentive or hyperactive/impulsive in nature, or a combination of both. It is strongly associated with deficits in executive functions and is characterized by marked impairments in inhibitory behaviour and WM particularly for visuo-spatial material [32].

Children with attention deficit hyperactivity disorder (ADHD) experience effusive interpersonal difficulties and peer disapproval that go beyond the diagnostic criteria. ADHD occurs in approximately $3-5 \%$ of the school-aged children with male to female ratios ranging from $4: 1$ to 9:1, depending on the setting. Although minimal research has been done on the effectiveness of technology for students with ADHD, technology is seen as one potential tool that offers promising results for these students. Technology enables the teacher to plan learning activities for students with short attention spans, allowing them to be actively involved in learning, and in turn even increase the student's motivation and confidence [33]. In the light of the above statements and with regards to computer assistance instructions (CAI), latest studies support that children with ADHD prefer to read short texts and watch short videos that include not many words. Also, the words should be used only for explanatory reasons, visual aids should be used to illustrate and support verbal information, and the rate of presentation should be slow. Additionally, low lights are suggested rather than bright lights for ADHD in order to concentrate on tasks [34].

However, in order to assist children with memory and attention problems a tool called cogmed was created [35]. This program has been marketed at schools to assist students' performance and is available as clinical practice for treatment of ADHD. Their developers claim that Cogmed training improves attention, concentration, focus, impulse control, social skills, and complex-reasoning skills by substantially and lastly improves working memory capacity. There are three types of Cogmed training; for preschoolers and older children which include several visuospatial and verbal memory tasks that have been embedded in videogames, each of which is performed for roughly 40 min a day, 5 days a week, for 5 weeks. Cogmed JM and Cogmed RM are respectively designed for preschoolers and older children. Specifically, an example of a visuospatial task that is included in Cogmed training is "Asteroids" which presents a field of several free-floating asteroids, a subset of which lights up, one-at-a-time and the child must reproduce the sequence via mouse click. Additionally, an example of a verbal task is "Input Module" in which a sequence of auditory digits is played and the child has to reproduce the sequence in reverse using a numberpad that is exposed on a robot's arm. However, although initial studies indicate that Cogmed is a successful inter- 
PAPER

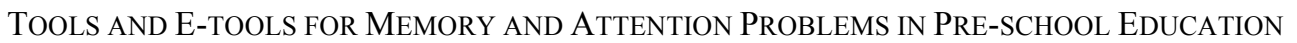

vention tool, there are some concerns about its validity and more research is needed to be done. There are studies that state that Cogmed is an unsubstantiated tool and so the future research should place greater emphasis on developing theoretically motivated accounts of working memory training [35].

Moreover, a recent study [36] resents the effects of a proposed CAI Module in Numeracy for kindergarten children with attention problems. The study is a developmental research whose primary goal was to develop a CAI Module on enhancing the numeracy skills of kindergarteners with ADHD based on the ARCS Model of Motivational Design by Keller \& Keller following the ADDIE Model of Instructional System Design by McArdle. The program allows each student to work with the Module for twenty minutes per session, asks each child to select and perform the task in the CAI Module and records the physical and verbal reactions of each student. According to this study, it can be concluded that the promising results of technology are aligned with the inattention, impulsivity, and hyperactivity symptoms of students with attention deficits and ADHD despite the fact that further improvements can still be incorporated to the proposed CAI Module.

Clarfield and Stoner [37] studied another example of a CAI intervention, which examined the effects of the Internet based reading program, Headsprout, on the academic performance of students with ADHD. The participants for this study were males in kindergarten and first grade who were diagnosed with ADHD and considered at risk for reading difficulties by their teachers. The data for this study indicated that the effects of CAI on oral reading fluency were improved for all the students and has been shown an increase active engagement time and decrease off task behaviour in children. Overall, the research supported the hypothesis that Headsprout would work as an appropriate and effective intervention for beginning readers with ADHD.

Additionally, another tool that seems promising in order to help pre-school children that face attention problems is an AR alphabet book, an Augmented Reality based book that teaches preschool children the alphabet. Used together with camera and computer, children could view the superimposed virtual alphabet in a fun and interactive way using the patterns as an interaction tool. Generally speaking, teaching young children could be difficult due to the fact that focus of young children is different from elderly since they could only focus on something for short period of time. However, introducing this way of learning teachers could grab the attention from children and therefore enhance teaching and learning for them. Fun learning includes learning through play, songs, painting, drama and the use of information and communication technology (ICT). Researches showed that fun learning also increase the ability to memorize and understand a concept besides the use of flashcard is one of the learning approaches that is used. The tangible manner of flashcard introduce the interaction of learning therefore it could create the fun and interactive learning. However, the potential of flash card could be further enhance through the use of AR technology, while displaying each alphabet upon presentation of its corresponding pattern marker, children have the opportunities to see $3 \mathrm{D}$ models of objects that begin with each alphabet character. Lastly, the results of the observed behaviours of the children suggest the potential of AR book as a tool that may create a constructive and joyful learning environment especially for this age [38].

In addition, Re \& Cornoldi [39] designed a research program intended to develop assessment and interventions tools for kindergarten children who face attention disorders and ADHD. Specifically, they developed two rating scales (one for teachers and one for parents), two neuropsychological tests, and an intervention program in order to promote controlled attention and working memory. Specifically, IPPDAI is an acronym for "Identificazione Precoce del Disturbo da Deficit di Attenzione/iperattivita' per Insegnanti' (Early Identification of ADHD for Teachers) and is a teacher rating scale for the early identification of children at risk for ADHD. The rating scale IPDDAI includes 18 items: 7 concerning inattention, 7 concerning hyperactivity/ impulsivity and 4 additional items concerning risk factors. These last items describe four aspects that can increase problematic behaviours of children (disadvantaged family, problematic situations at home, poor cognitive abilities, emotional and relational problems). The IPDDAI scale has been validated and standardised for the Italian population and demonstrates good psychometric properties and predictive validity [40].

Furthermore, IPDDAG [41] is an acronym for the Italian expression 'Identificazione Precoce del Disturbo da Deficit di Attenzione/ iperattivita' per Genitori' (Early identification of ADHD for parents). IPDDAG is the complementary form of IPDDAI, because it is the parent version of a rating scale for early identification of children at risk for ADHD. Using both rating scales, it is possible to know the child's behaviours in the most important contexts in which a child lives. Comparing evaluations of parents and teachers, it is easy to identify those children who are likely to develop ADHD in the future. IPDDAG is parallel to the IPDDAI, and includes the 14 symptoms considered most representative and discriminative in a preliminary investigation with parents (Riello et al., 2005). The test consists of 19 items, 7 for inattention, 7 for hyperactivity/impulsivity and the remaining 5 for "risk factors", just as IPDDAI. Risk factors concern poor cognitive abilities, languages difficulties aggressive behaviours, emotional problems and relational problems.

Also, Walk/No walk is a paper and pencil test that evaluates control of attention and the inhibition of an ongoing response. The test asks from children to follow a series of directions and stop an ongoing response when a particular signal occurs. The test includes two A4 sheets of paper in which 20 stairs are drawn with a little frog at the first step. The child is asked to cancel a step each time he hears the "GO" signal, while he has to stop every time he hears the "STOP" signal. The "STOP" signal is very similar to the "GO" signal but is different in its ending. Obviously, for every trail there are many go signals and only 1 stop signal. There are two training trials that can be used several times until the child demonstrates understanding of the task. The difficulty of this task is that the stop signal is made in two parts, and the first part has the same sound of the go signal. Therefore, the child must wait to hear the entire sound before providing the response, in order to understand if it is a go or stop signal. However, three different types of errors can be appeared. Firstly, a child "goes" even with the presence of the stop signal and so he cannot inhibit the ongoing response. Secondly, a child "stops" before the appearance of the stop signal and lastly the child is not able to maintain 
attention along the trial and to move in correspondence with the sounds. Usually the first type of error is the most frequent, and describes lack of inhibitory control. The second type of error could be an expression of anxiety. The third type of error also is frequent, and describes lack of controlled prolonged attention [41].

Last but not least, in a recent conducted study the Dual Request Selective Task (DRST) that is a visual spatial working memory tool, assess children's ability to control information in working memory, and to inhibit irrelevant information. The test is based on a 4.4 matrix and is divided into 16 cells. The matrix is blank with a red square, situated always in the same position. DRST requires the examinee to remember the first position indicated by the experimenter and to clap hands when the experimenter indicates the red square. There are 10 trials, ordered for difficulty level while the difficulty depends on the number of cells touched by a frog. There are two trials for each level. The child must complete the entire task. Before starting with the experimental session, the experimenter proposes some practice trials, moving the frog through 2 cells only and when he is completely sure that the child has understood the task, he starts with the experimental session. A trial is considered correct only when the child carries out both tasks correctly, clapping hands and remembering the first position while the average time for this task is about $10 \mathrm{~min}$ [42].

\section{CONCLUSIONS}

During this review paper an attempt was made to present some of the most significant tools and e-tools that are used in order to diagnose and support preschool children who face memory and attention problems. The purpose of this article was to make a list of tools and e-tools that are used by teachers, specialists and parents in order to diagnose and assess memory and attention problems in kindergarten children. Diagnostic and intervention tools that are used worldwide in different countries were presented and a brief description of their role was discussed. Despite the fact that the list is representative of the most important tools that are used worldwide it is obvious that there is need for development and design of tools with and without the support of ICT's, which help children with such problems. Our study showed that there is place for research while we did not have a satisfactory number of findings. Furthermore, there is the general consensus that the use of ICT 's plays a significant role in learning and teaching ensuring and enhancing the learning skills of kindergarten children who face memory and attention difficulties. In addition, there are also several fields that require further research such as investigations into the reliability and validity of the diagnostic ICT tools, adaptations of diagnostic and intervention tools to the various needs of children and therapists, and development of more programs in different languages for the above areas at this age. Last but not least, we consider that in general the field of pre- school education and the area of a pre-school child' $\mathrm{s}$ development calls for more investigation besides we hope that the results of the current study are encouraging.

\section{REFERENCES}

[1] Gillard, S., Bailey, D., \& Nolan, E.: Ten reasons for IT educators to be early adopters of IT innovations. Journal of Information Technology Education: Research, 7(1), pp. 21-33 (2008).
[2] Toki, E. I., \& Pange, J.: Traditional and computer-based evaluation of preschoolers' oral language in Greek-A review of the literature. Sino-US English Teaching, 9(1), pp. 840-845 (2012)

[3] Toki, E. I., \& Pange, J.: E-learning activities for articulation in speech language therapy and learning for preschool children. Procedia-Social and Behavioral Sciences, 2(2), pp. 4274-4278 (2010). http://dx.doi.org/10.1016/j.sbspro.2010.03.678

[4] Natsiopoulou, T., \& Bletsou, M.: Greek preschoolers' use of electronic media and their preferences for media or books. International Journal of Caring Sciences, 4(2), pp. 97-104 (2011).

[5] Steele, M. M.: Making the case for early identification and intervention for young children at risk for learning disabilities. Early Childhood Education Journal, 32(2), pp.75-79 (2004). http://dx.doi.org/10.1007/s10643-004-1072-x

[6] Stevens, C. : Information and communication technology, special educational needs and schools: a historical perspective of UK government initiatives. In: ICT and Special Educational Needs: a Tool for Inclusion, Florian, L., Hegarty, J. (eds.) Open University Press, Buckingham pp. 21-34 (2004).

[7] National Association for the Education of Young Children (1999) Technology and young children: What parents should know. Retrieved from: http://www.naeyc.org/resources/eyly/1996/09b.htm

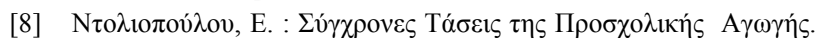

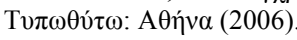

[9] Blackwell,K., Cepeda,N., \& Munakata,Y.: When simple things are meaningful: Working memory strength predicts children's cognitive flexibility. Journal of Experimental Child Psychology 103, pp. 241-249 (2009). http://dx.doi.org/10.1016/j.jecp.2009.01.002

[10] McPake, J., Plowman, L., \& Stephen, C.: Pre $\square$ school children creating and communicating with digital technologies in the home. British Journal of Educational Technology, 44(3), pp. 421-431 (2013). http://dx.doi.org/10.1111/j.1467-8535.2012.01323.x

[11] Engel de Abreu, P., Conway, A., \& Gathercole, S.: Working memory and fluid intelligence in young children. Intelligence 38 , pp. 552-561 (2010). http://dx.doi.org/10.1016/j.intell.2010.07.003

[12] Drigas,A., \& Dourou,A.: A review on ICT based applications for intervention and assistance of people with memory deficits. I-JET 8, pp. 1-3(2013). http://dx.doi.org/10.3991/ijet.v8i5.3009

[13] Westerberg, H., Hirvikoski, T., Forssberg, H., \& Klingberg, T.: Visuo-spatial working memory span: A sensitive measure of cognitive deficits in children with ADHD. Child Neuropsychology, 10(3), pp. 155-161(2004). http://dx.doi.org/10.1080/092970404 $\underline{09609806}$

[14] American Psychiatric Association. : DSM 5. American Psychiatric Association (2013).

[15] Re, A. M., Mirandola, C., Esposito, S. S., \& Capodieci, A.: Spelling errors among children with ADHD symptoms: The role of working memory. Research in developmental disabilities, 35(9), pp. 2199-2204 (2014). http://dx.doi.org/10.1016/j.ridd. 2014.05.010

[16] Blurton, C.: New Directions of ICT-Use in Education. Learning without frontiers. UNESCO World Communication and Information Report, 2007.

[17] Finnis, J.: Myths and facts of learning technology. TechLEARNING. Retrieved from http://www.techlearning.com/story/show Article.jhtml?articleID=22101447 2004.

[18] Shipstead, Z., Hicks, K.,\& Engle, R,: Cogmed working memory training: Does the evidence support the claims? Journal of Applied Research in Memory and Cognition 1, pp. 185-193(2012). http://dx.doi.org/10.1016/j.jarmac.2012.06.003

[19] Alloway, T. P., Gathercole, S. E., Kirkwood, H., \& Elliott, J.: The working memory rating scale: A classroom-based behavioral assessment of working memory. Learning and Individual Differences, 19(2), pp. 242-245 (2009). http://dx.doi.org/10.1016/j.lin dif.2008.10.003

[20] Aristodemou, E., Taraszow, T., Laouris, Y., Papadopoulos, T., \& Makris, P. : Prediction of Reading Performance Using the MAPS (Mental Attributes Profiling System) Multimodal Interactive ICT Application. In The 7th European Conference on ELearning:[hosted by the University of Cyprus]: Grecian Bay Hotel, Agia Napia, Cyprus, 6-7 November 2008 (p. 58). Academic Conferences Limited (2008). 
[21] Singleton. C.: Using computer-based assessment to identify learning problems. In: ICT and Special Educational Needs, L. Florian and J. Hegarty, Eds, Open University Press pp. 46-63 (2004).

[22] Toki, E., Pange, J., \& Mikropoulos, T.: An online expert system for diagnostic assessment procedures on young children oral speech and language. Procedia Computer Science 14, pp. $428-$ 437(2012). http://dx.doi.org/10.1016/j.procs.2012.10.049

[23] Galecka, J.: How Technology Helped Create National Standards for Early and Special Needs Education (2012).

[24] St Clair-Thompson, H.L.: The influence of strategies upon relationships between working memory and cognitive skills. Memory, 15, pp. 353-365 (2007). http://dx.doi.org/10.1080/096582107 $\underline{01261845}$

[25] Leedale, R., Singleton, C., \& Thomas, K. : Memory booster (computer program and manual). Beverly, East Yorkshire: Lucid Research (2004).

[26] Pickering,S. \&Gathercole, S.: Distinctive working memory profiles in children with special educational needs, Educational Psychology: An International Journal of Experimental Educational Psychology, 24 pp. 393-408 (2004). http://dx.doi.org/10.1080/ 0144341042000211715

[27] Gathercole, S, Alloway,T., \& Pickering, S.: Verbal and Visuospatial Short-Term and Working Memory in Children: Are They Separable? Child Development 77, pp. 1698 - 1716 (2006). http://dx.doi.org/10.1111/j.1467-8624.2006.00968.x

[28] Nikiforidou, Z., \& Pange, J.: "Shoes and Squares": A computerbased probabilistic game for preschoolers. Procedia Social and Behavioral Sciences 2, pp. 3150-3154 (2010). http://dx.doi.org/10.1016/j.sbspro.2010.03.480

[29] Toki, E. I., \& Pange, J.: E-learning activities for articulation in speech language therapy and learning for preschool children. Procedia-Social and Behavioral Sciences, 2(2), pp. 4274-4278(2010). http://dx.doi.org/10.1016/j.sbspro.2010.03.678

[30] Brown, A. L., \& Kane, M. J.: Preschool children can learn to transfer: Learning to learn and learning from example. Cognitive Psychology, 20 (4), pp. 493-523 (1988). http://dx.doi.org/10.1016/ 0010-0285(88)90014-X

[31] Martinussen, R., Hayden, J., Hogg-Johnson, S., \& Tannock, R.: A meta-analysis of working memory impairments in children with attention-deficit/hyperactivity disorder. Journal of the American Academy of Child \& Adolescent Psychiatry, 44(4), pp. 377-384 (2005). http://dx.doi.org/10.1097/01.chi.0000153228.72591.73

[32] Krain, A. L., \& Castellanos, F. X.: Brain development and ADHD. Clinical psychology review, 26(4), pp. 433-444 (2006). http://dx.doi.org/10.1016/j.cpr.2006.01.005

[33] Gau, S. S. F., \& Chiang, H. L.: Association between early attention-deficit/hyperactivity symptoms and current verbal and visuospatial short-term memory. Research in developmental disabilities, 34(1), 10-720. Behavior?.Journal of Educational Multimedia and Hypermedia, 13(2), pp.109-128 (2013).

[34] Solomonidou, C., Garagouni-Areou, F., \& Zafiropoulou, M.: Information and communication technologies (ICT) and pupils with attention deficit hyperactivity disorder (ADHD) symptoms: Do the software and the instruction method affect their behavior? Journal of Educational Multimedia and Hypermedia, 13(2), pp. 109-128 (2004)

[35] Shipstead, Z., Hicks, K. L., \& Engle, R. W.: Cogmed working memory training: Does the evidence support the claims?. Journal of Applied Research in Memory and Cognition, 1(3), pp. 185-193 (2012). http://dx.doi.org/10.1016/j.jarmac.2012.06.003
[36] Alontaga, J. V. Q., Lim, E., Balaji, S., Murugaiyan, M. S., Holly Deviarti, S. E., Heny Kurniawati, S. E., \& Heri Sukendar, W. D. : A computer-assisted instruction module on enhancing numeracy skills of preschoolers with attention-deficit hyperactivity disorder. International Journal of Information Technology and Business Management, 2(1), pp. 1-15 (2012).

[37] Clarfield, J., \& Stoner, G. : Research Brief: The Effects of Computerized Reading Instruction on the Academic Performance of Students Identified with ADHD. School Psychology Review (2005).

[38] Rambli, D. R. A., Matcha, W., \& Sulaiman, S.: Fun Learning with AR Alphabet Book for Preschool Children. Procedia Computer Science, 25, pp. 211-219 (2013). http://dx.doi.org/10.1016/ j.procs.2013.11.026

[39] Re, A. M., \& Cornoldi, C. (submitted). Parents' and teachers' assessment of ADHD symptoms in preschool Italian children. Padova, Italy: University of Padova, Department of General Psychology.

[40] Cornoldi, C., Marzocchi, G. M., Belotti, M., Caroli, M. G., De Meo, T., \& Braga, C. (2001). Working memory interference control deficit in children referred by teachers for ADHD symptoms. Child Neuropsychology, 7, pp. 230-240 (2001). http://dx.doi.org/10.1076/chin.7.4.230.8735

[41] Riello, M., Re, A. M., \& Cornoldi, C.: Costruzione di uno strumento rivolto alla famiglia per l'identificazione precoce del DDAI. [Construction of a tool based upon parents ratings for the early identification of ADHD children]. Difficolta` di attenzione e iperattivita', 1, pp. 9-21 (2005).

[42] Lanfranchi, S., Cornoldi, C., \& Vianello, R.: Verbal and visuospatial working memory deficit in children with Down syndrome. American Journal on Mental Retardation, 109, pp. 456-466 (2004). http://dx.doi.org/10.1352/0895-8017(2004)109<456:VAV $\mathrm{WMD}>2.0 . \mathrm{CO} ; 2$

\section{AUTHORS}

Athanasios Drigas is a Research Director at N.C.S.R. Demokritos. He is the Coordinator of Telecoms Lab and founder of Net Media Lab since 1996. From 1985 to 1999 he was the Operational manager of the Greek Academic network. He has been the Coordinator of Several International Projects, in the fields of ICTs, and e-services (elearning, e-psychology, e-government, e-inclusion, eculture etc). He has published more than 270 articles, 7 books, 25 educational CD-ROMs and several patents. He has been a member of several International committees for the design and coordination of Network and ICT activities and of international conferences and journals. (e-mail: dr@iit.demokritos.gr).

Georgia Kokkalia (MSc in Specific Learning Difficulties) is a Special Education Teaching Professional. She has participated in various research projects regarding the use of Information and Communication Technologies (ICTs) in Special Education and in Kindergarten. (e-mail: gioulina@hotmail.com).

Submitted 18 May 2015. Published as resubmitted by the authors 10 October 2015. 